\title{
Muscle enzyme activity and insulin sensitivity in Type 1 (insulin-dependent) diabetes mellitus
}

\author{
Y.T. Kruszynska, G. Petranyi, P. D. Home, R. Taylor and K. G. M.M. Alberti \\ Department of Medicine, University of Newcastle upon Tyne, Newcastle upon Tyne, UK
}

Summary. The mechanisms of insulin insensitivity in diabetes are poorly understood. We have therefore assessed the relationship between glucose disposal during a euglycaemic clamp, muscle glycogen formation, and the activities of insulin regulated enzymes within skeletal muscle in five Type 1 (insulin-dependent) diabetic patients, both on conventional injection therapy ( $\mathrm{HbA}_{1} 11.0 \pm 1.0(\mathrm{SD}) \%$ ) and after 6 weeks continuous subcutaneous insulin infusion $\left(\mathrm{HbA}_{1} 7.6 \pm 1.4 \%\right.$, $p<0.01$ ). On both regimens, overnight euglycaemia before the clamp was maintained with an intravenous insulin infusion. The increase in clamp glucose requirements (insulin $0.1 \mathrm{U}$. $\mathrm{kg}^{-1} \cdot \mathrm{h}^{-1}$ ) between injection therapy and continuous subcutaneous insulin infusion was significant $(6.2 \pm 0.9$ (SE) to $7.0 \pm 0.9 \mathrm{mg} \cdot \mathrm{kg}^{-1} \cdot \mathrm{min}^{-1}, p<0.05$ ), but small compared to differences between subjects. Glucose requirement remained lower than in control subjects $\left(10.4 \pm 0.7 \mathrm{mg} \cdot \mathrm{kg}^{-1} \cdot \mathrm{min}^{-1}\right.$, $p<0.05$ ). The increase in muscle glycogen with the clamp was slightly higher on continuous subcutaneous insulin infusion $(9.5 \pm 2.5 \mathrm{mg} / \mathrm{g}$ protein) than on injection therapy $(8.5 \pm$ $2.4 \mathrm{mg} / \mathrm{g}, p<0.05)$, but less than in control subjects $(17.9 \pm$ $2.1 \mathrm{mg} / \mathrm{g}, p<0.05)$. The expressed activity of glycogen synthase and pyruvate dehydrogenase increased significantly between fasting and the end of the clamps in the patients $(p<$ 0.001 and $<0.005$ ), but was not significantly different between the two treatment regimens. Expressed glycogen synthase ac- tivity at the end of the clamp was lower on both treatments than in control subjects $(p<0.05)$. Both enzyme activities were, however, highly correlated with glucose requirement between patients, $(r=0.89-0.94, p<0.05-0.02)$, and glycogen synthase was similarly correlated in the control subjects $(r=0.84, p<0.05)$. Patients had significantly different enzyme activities, glucose requirement, and glycogen stored by analysis of variance $(p<0.05-0.01)$. Correlation of each enzyme activity between subjects on the two treatment regimens was also high $(r=0.94-0.98, p<0.02-0.01)$. At the end of the clamp the enzyme activities were themselves closely related (injections $r=0.99, p<0.001$; infusion $r=0.88, p<0.05$ ), and glycogen synthase activity predicted muscle glycogen deposition ( $r=0.94-0.97, p<0.02-0.01$ ). We suggest that: (1) preceding metabolic control has a relatively small influence on whole body insulin sensitivity measured immediately after careful overnight control; (2) insulin sensitivity derived from glucose clamp data is strongly related to skeletal muscle glycogen deposition and skeletal muscle enzyme activities.

Key words: Type 1 diabetes, continuous subcutaneous insulin infusion, insulin sensitivity, insulin resistance, glucose clamp, skeletal muscle, glycogen, glycogen synthase, pyruvate dehydrogenase.
People with insulin-treated diabetes have been shown to be relatively insensitive to the action of insulin, as measured by the euglycaemic clamp technique [1]. Treatment with continuous subcutaneous insulin infusion (CSII) has been reported to improve this sensitivity, though it is probably not normal $[2,3]$. The tissue responsible for insulin insensitivity at the doses used for the euglycaemic clamp is likely to be skeletal muscle, as a high proportion of insulin-dependent glucose disposal can be accounted for by this tissue, at least in normal subjects $[4,5]$. However, the biochemical site of the metabolic defect underlying insulin insensitivity remains uncertain.

The primary aim of the present study was to assess the relationship between clamp glucose disposal, muscle glycogen formation, and the activities of insulin regulated enzymes within skeletal muscle. This relationship was investigated both between periods of poor and good control, achieved with conventional injection therapy and continuous subcutaneous insulin infusion, and studied between patients. Unlike the earlier studies $[2,3]$ overnight control prior to the clamp studies was 
Table 1. Characteristics of the patients studied

\begin{tabular}{|c|c|c|c|c|c|c|}
\hline $\begin{array}{l}\text { Patient } \\
\text { no. }\end{array}$ & $\begin{array}{l}\text { Sex } \\
(M / F)\end{array}$ & $\begin{array}{l}\text { Age } \\
\text { (years) }\end{array}$ & $\begin{array}{l}\text { Body mass } \\
\text { index } \\
\left(\mathrm{kg} / \mathrm{m}^{2}\right)\end{array}$ & $\begin{array}{l}\mathrm{HbA}_{1} \\
(\%)\end{array}$ & $\begin{array}{l}\text { Insulin } \\
\text { dose } \\
\text { (U/day) }\end{array}$ & $\begin{array}{l}\text { Duration } \\
\text { of diabetes } \\
\text { (years) }\end{array}$ \\
\hline 1 & M & 33 & 23 & 12.7 & 58 & 4 \\
\hline 2 & $\mathrm{~F}$ & 27 & 27 & 10.6 & 46 & 10 \\
\hline 3 & M & 23 & 22 & 10.3 & 40 & 15 \\
\hline 4 & $\mathbf{M}$ & 52 & 27 & 10.2 & 76 & 23 \\
\hline 5 & $\mathbf{M}$ & 44 & 27 & 11.2 & 50 & 14 \\
\hline
\end{tabular}

achieved with intravenous insulin infusion to ensure that any differences found reflected only long term control.

Glucose entering the myocyte may be stored as glycogen, or may be oxidised via glycolysis and the Krebs cycle. We have studied glycogen synthase and pyruvate dehydrogenase as major insulin regulated enzymes on the specific pathways of glucose storage and glucose oxidation respectively. Muscle biopsies were performed on a major muscle of mixed fibre type (vastus lateralis) so as to be representative of whole body skeletal muscle. To avoid the effects of anaesthetics and muscle relaxants, and to allow correlations with concomitant clamp studies, muscle biopsy was performed under local anaesthetic on otherwise healthy Type 1 diabetic patients.

\section{Subjects and methods}

\section{Patients}

Five Type 1 diabetic patients ( 4 male, 1 female) were recruited. Approval for the study was given by the local ethical committee, and informed consent by each patient. Their clinical characteristics are given in Table 1. All were otherwise well, and taking no other drug therapy. One had had photocoagulation for preproliferative retinopathy, the others being free of evidence of microvascular disease. Renal and liver function tests were normal. The patients selected did not regularly undertake strenuous occupational or recreational exercise. They were all on diets unrestricted in unrefined carbohydrate. In each case they were selected as having rather poor control, to provide a contrast against the second part of the study. At entry to the study they were already being treated with a twice daily regimen of short and intermediate acting highly purified porcine insulin formulations. No patient was taking any other medication.

Each patient was studied on two occasions, 8 to 10 weeks apart. The first study was performed on their usual insulin injection regimen, and the second 6 weeks after establishing good control obtained with CSII. The order of study was not randomised to prevent carry over effects of a period of intensive control. Diet was not altered between the two studies.

Two seven-point home-collected laboratory-measured blood glucose profiles were obtained using Sarstedt fluoride tubes (Leicester, UK) prior to the first study, and then once or twice weekly during CSII. Self blood glucose monitoring was performed at least twice daily using the BM Glycemie $20-800 \mathrm{R}$ (BCL, Lewes, UK) reagent strip. Insulin doses on CSII were adjusted to maintain blood glucose concentrations between 3 and $5 \mathrm{mmol} / 1$ pre-prandially, and between 4 and $7 \mathrm{mmol} / 11.5 \mathrm{~h}$ post prandially. Glycosylated haemoglobin was measured at entry to the study and repeated twice-weekly during CSII.
Six normal subjects ( 5 male, 1 female) formed the control group. They were aged $23-49$ years, and of body mass index $21-27 \mathrm{~kg} / \mathrm{m}^{2}$. They were similar to the patients in terms of exercise undertaken. These subjects were studied on one occasion only, after admission to hospital overnight.

\section{Study protocol}

Patients were admitted to hospital on the evening before the study, having taken a maximum of $10 \mathrm{U}$ short-acting insulin only prior to their evening meal at 18.00 hours. Two IV cannulae were inserted into forearm veins on the evening of admission. One cannula was used for infusion of insulin (Human Actrapid, Novo, Basingstoke, UK) diluted in Haemaccel (Hoechst, Frankfurt am Main, FRG). The second cannula was inserted retrogradely in a distal vein, and was used for intermittent blood sampling, being flushed after use with $0.15 \mathrm{~mol} / 1$ $\mathrm{NaCl}$ in water.

The patients were fasted from 21.00 hours and blood glucose maintained at $4.3 \mathrm{mmol} / 1$ overnight by adjustment of the IV insulin infusion. Control subjects were also fasted from 21.00 hours. A basal blood sample was taken at 07.00 hours for estimation of blood glucose, plasma free insulin, $\mathrm{HbA}_{1}$, and serum triglycerides and cholesterol. A needle biopsy of the vastus lateralis muscle (200 to $250 \mathrm{mg}$ ) was then performed using a UCH-type needle [6]. The tissue was frozen immediately in liquid nitrogen.

After the basal biopsy the IV insulin infusion was increased to $0.1 \mathrm{U} \cdot \mathrm{kg}^{-1} \cdot \mathrm{h}^{-1}$ from a syringe pump. Blood glucose concentration was measured at 5-min intervals by the glucose oxidase method (Yellow Springs Glucose Analyser, Clandon Scientific, London, UK), and clamped at $4.0 \mathrm{mmol} / \mathrm{l}$ for $4 \mathrm{~h}$ by adjustment of the rate of infusion of a solution of $20 \%(\mathrm{w} / \mathrm{v})$ glucose in water [7]. Glucose turnover was not measured, as hepatic glucose output is effectively suppressed in Type 1 diabetic patients at the insulin dose used [1]. Samples for free insulin measurement were taken at $30 \mathrm{~min}$ intervals throughout the clamp, centrifuged briefly and immediately extracted with polyethyleneglycol 6000 [8]. In control subjects insulin was measured on serum, the results being identical to globulin extracted plasma for control subjects in our assay [8]. A second biopsy was performed on the contralateral vastus lateralis during the last half hour of the clamp, metabolic data therefore being gathered in the preceding half hour, from +180 to $+210 \mathrm{~min}$.

For the second study on CSII, subcutaneous infusion of insulin was discontinued at 19.00 hours, and blood glucose maintained overnight as before. The clamp, muscle biopsies and clearance study were then repeated.

\section{Muscle glycogen synthase activity}

Muscle glycogen synthase activity was measured by the method of Golden et al. [9] within $24 \mathrm{~h}$ of obtaining the tissue. Samples of muscle ( $\sim 0.05 \mathrm{~g}$ ) were homogenised (Polytron Kinematica, Lucerne, Switzerland) in $800 \mathrm{ul}$ of Tris $/ \mathrm{HCl}$ buffer, $\mathrm{pH} 7.8$, containing $10 \mathrm{mmol} / 1 \mathrm{ED}-$ TA, $5 \mathrm{mmol} / 1$ dithiothreitol, $50 \mathrm{mmol} / \mathrm{l} \mathrm{NaF}$ and $2.5 \mathrm{~g} / 1$ rabbit liver glycogen type III (Sigma, Poole, Dorset, UK). The homogenate was centrifuged at $10000 \mathrm{~g}$ for $30 \mathrm{~s}$ in a micro-centrifuge and the supernatant used for glycogen synthase assay by measuring the incorporation of UDP-U ${ }^{14} \mathrm{C}$-glucose into glycogen at $30^{\circ} \mathrm{C}$. The final concentration of UDP-glucose in the assay was $6.7 \mathrm{mmol} / 1$. Total glycogen synthase activity was measured in the presence of $10 \mathrm{mmol} / 1$ glucose- 6 -phosphate. One unit of enzyme activity is defined as the amount of enzyme catalysing the transfer of $1 \mu \mathrm{mol}$ of glucose from UDP-glucose into glycogen per min at $30^{\circ} \mathrm{C}$.

\section{Muscle pyruvate dehydrogenase activity}

Skeletal muscle pyruvate dehydrogenase was measured spectrophotometrically [10] by coupling the acetyl CoA generated in the assay to p-aminophenylazobenzene sulphonic acid by arylamine acetyl transferase prepared from pigeon liver [11]. Muscle $(\sim 0.1 \mathrm{~g})$ was homoge- 


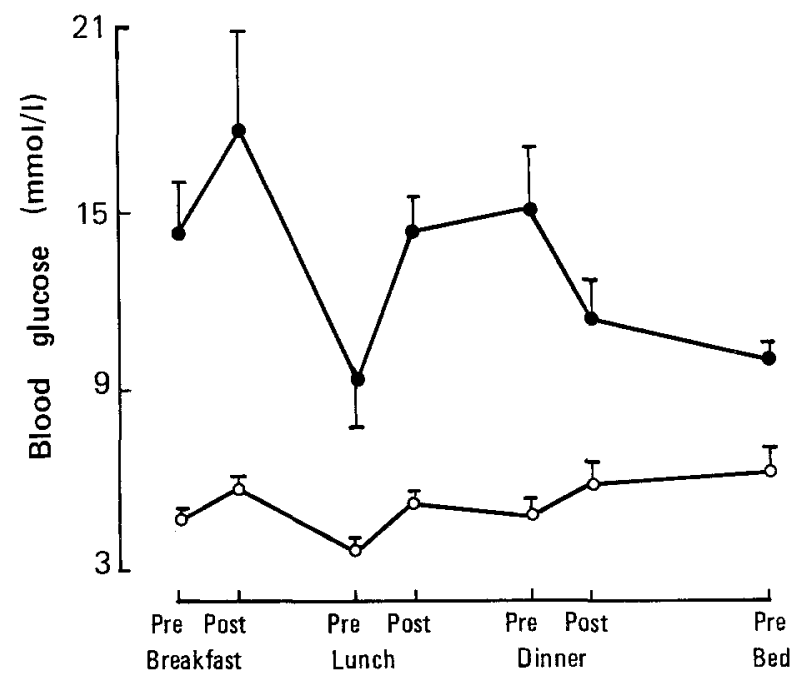

Fig.1. Home-collected laboratory-measured blood glucose profiles in the five Type 1 diabetic patients studied. Samples were collected while on unchanged conventional injection therapy (- $)$, or during the period on continuous subcutaneous insulin infusion (CSII) $(\mathrm{O}-\mathrm{O})$

Table 2. Fasting metabolic characteristics of the control subjects and 5 Type 1 diabetic patients after overnight insulin infusion following periods of treatment by conventional injection therapy and continuous subcutaneous insulin infusion

\begin{tabular}{lccl}
\hline & $\begin{array}{l}\text { Injection } \\
\text { therapy }\end{array}$ & CSII & $\begin{array}{l}\text { Control } \\
\text { subjects }\end{array}$ \\
\hline Blood glucose $(\mathrm{mmol} / \mathrm{l})$ & $4.4 \pm 0.5$ & $4.2 \pm 0.2$ & $4.4 \pm 0.1$ \\
Insulin infusion rate $(\mathrm{U} / \mathrm{h})$ & $1.1 \pm 0.3$ & $1.2 \pm 0.3$ & - \\
Plasma free insulin $(\mathrm{mU} / \mathrm{l})$ & $13.0 \pm 5.0$ & $10.0 \pm 3.0$ & $6.0 \pm 1.0$ \\
Plasma triglyceride $(\mathrm{mmol} / \mathrm{l})$ & $0.97 \pm 0.12$ & $0.68 \pm 0.10^{\mathrm{a}}$ & $0.85 \pm 0.07$ \\
Plasma cholesterol $(\mathrm{mmol} / \mathrm{l})$ & $5.2 \pm 0.6$ & $4.6 \pm 0.5^{\mathrm{a}}$ & $4.1 \pm 0.2$ \\
HDL-cholesterol $(\mathrm{mmol} / \mathrm{l})$ & $1.2 \pm 0.1$ & $1.2 \pm 0.1$ & $1.0 \pm 0.1$ \\
\hline
\end{tabular}

Mean \pm SEM. ${ }^{\mathrm{a}} p<0.02$ compared with injection therapy; ${ }^{\mathrm{b}}$ serum direct insulin in the control subjects

nised at $0{ }^{\circ} \mathrm{C}$ (Polytron Kinematica, setting No 4, 30s) in $800 \mu \mathrm{l}$ of $100 \mathrm{mmol} / \mathrm{l}$ Tris $/ \mathrm{HCl}$ buffer, $\mathrm{pH} 7.3$, containing dithiothreitol $(2.0 \mathrm{mmol} / \mathrm{l})$, EDTA $(2.0 \mathrm{mmol} / 1), 0.1 \%(\mathrm{v} / \mathrm{v})$ Triton X100 and $50 \mathrm{ml} / 1 \mathrm{rat}$ serum. Samples were freeze-thawed three times and centrifuged at $10000 \mathrm{~g}$ for $45 \mathrm{~s}$. The final composition of the buffer was $100 \mathrm{mmol} / 1 \mathrm{Tris} / \mathrm{HCl}, 0.7 \mathrm{mmol} / 1$ EDTA, $1.2 \mathrm{mmol} / 1$ dithiothreitol, $1.0 \mathrm{mmol} / 1 \mathrm{MgCl}_{2}, 2.0 \mathrm{mmol} / 1 \mathrm{NAD}, 1.0 \mathrm{mmol} / 1$ thiamine pyrophosphate, $1.0 \mathrm{mmol} / 1$ pyruvate and $0.2 \mathrm{mmol} / 1$ coenzyme $A$. The decrease in absorbance was followed at $460 \mathrm{~nm}$. For determination of total pyruvate dehydrogenase, extracts were incubated with purified bovine kidney PDH phosphatase (generously donated by Dr S Yeaman, Department of Biochemistry, University of Newcastle upon Tyne, UK) for $25 \mathrm{~min}$ at $30^{\circ} \mathrm{C}$ in the presence of $10 \mathrm{mmol} / 1 \mathrm{MgCl}_{2}$, $1 \mathrm{mmol} / 1 \mathrm{CaCl}_{2}$ and $10 \mathrm{mmol} / 1$ dichloroacetate. One unit of enzyme is defined as the activity converting $1 \mu \mathrm{mol} / \mathrm{min}$ of pyruvate at $30^{\circ} \mathrm{C}$.

\section{Other analyses}

Skeletal muscle glycogen was determined by the amyloglucosidase method [12]. Protein was determined by the method of Lowry [13]. Plasma free insulin was determined on the frozen PEG extracts using a human insulin standard [8]. Glycosylated haemoglobin was determined by an electrophoretic method (Corning Instruments), reference range 5.5 to $7.5 \%$. Triglycerides and cholesterol were measured by standard enzymatic methods.

\section{Statistical analysis}

Results are expressed as mean \pm SEM unless otherwise indicated. The significance of differences was tested by Student's paired or unpaired t-test or analysis of variance as appropriate. Correlations were sought by Pearson's least squares method.

\section{Results}

\section{Metabolic control}

Glycosylated haemoglobin was $11.0 \pm 1.0$ (SD) $\%$ on injection therapy before the first study, and $7.6 \pm 1.4 \%$ after CSII before the second study $(p<0.01)$. This improvement in metabolic control was also evident from the home collected, laboratory measured blood glucose profiles (Fig.1). Body weight did not change between the two studies (injections $71 \pm 6 \mathrm{~kg}$, CSII $72 \pm 5 \mathrm{~kg}$ ), while the daily insulin dose remained similar $(54 \pm 6$ versus $50 \pm 6 \mathrm{U} /$ day, NS).

Immediately before the first biopsy on each day, fasting blood glucose concentrations were similar and were obtained with similar insulin infusion rates (Table 2). Plasma free insulin concentrations were also similar at this time (Table 2). Serum cholesterol and triglyceride concentrations were both significantly reduced after the period of treatment with CSII $(p<0.02$, Table 2).

\section{Glucose clamp studies and insulin pharmacokinetics}

Plasma free insulin concentration during the clamp from +90 to +210 min was not significantly different in patients on CSII $(89 \pm 3 \mathrm{mU} / 1)$ than on injection therapy $(86 \pm 4 \mathrm{mU} / 1)$. Serum insulin in control subjects was $77 \pm 5 \mathrm{mU} / 1$. The blood glucose concentration from +180 to $+210 \mathrm{~min}$ was $4.0 \pm 0.1$ ( $\pm \mathrm{SD}$ ) $\mathrm{mmol} / \mathrm{l}$ on injection therapy, $4.0 \pm 0.1 \mathrm{mmol} / 1$ on CSII, and $4.0 \pm$ $0.1 \mathrm{mmol} / 1$ in the control subjects. The coefficient of variation of blood glucose calculated for each patient was $2.8 \pm 0.9( \pm \mathrm{SD}) \%, 2.7 \pm 1.1 \%$, and $2.4 \pm 0.9 \%$ respectively. Glucose requirement rose to $6.2 \pm 0.9$ (injections) and $7.0 \pm 0.9$ (CSII) $\mathrm{mg} \cdot \mathrm{kg}^{-1} \cdot \mathrm{min}^{-1}(p<0.05)$ for the same time period. This difference was, however, small compared to that between patients (mean range 3.45 to $8.35 \mathrm{mg} \cdot \mathrm{kg}^{-1} \cdot \mathrm{min}^{-1}, \mathrm{~F}=36.6, p<0.005$ ). On both occasions it was significantly lower than in normal subjects $\left(10.4 \pm 0.7 \mathrm{mg} \cdot \mathrm{kg}^{-1} \cdot \mathrm{min}^{-1}, p<0.05\right)$.

\section{Skeletal muscle glycogen concentration and glycogen synthase activity}

Muscle glycogen concentration in the overnight fasted patients was identical on the two study days, injection therapy $58.5 \pm 3.2 \mathrm{mg} / \mathrm{g}$ protein and CSII $59.4 \pm$ $3.8 \mathrm{mg} / \mathrm{g}$, and no different from the control subjects $(59.6 \pm 1.4 \mathrm{mg} / \mathrm{g})$. The increase in muscle glycogen concentration between the basal and clamp biopsies 


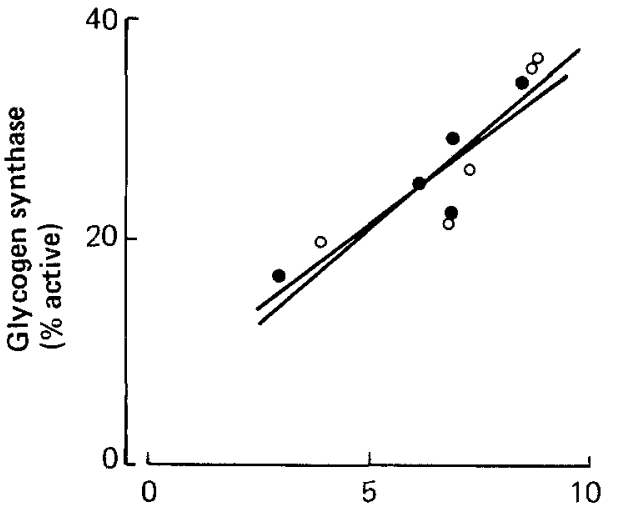

Glucose requirement $\left(\mathrm{mg} \cdot \mathrm{kg}^{-1} \cdot \mathrm{min}^{-1}\right)$

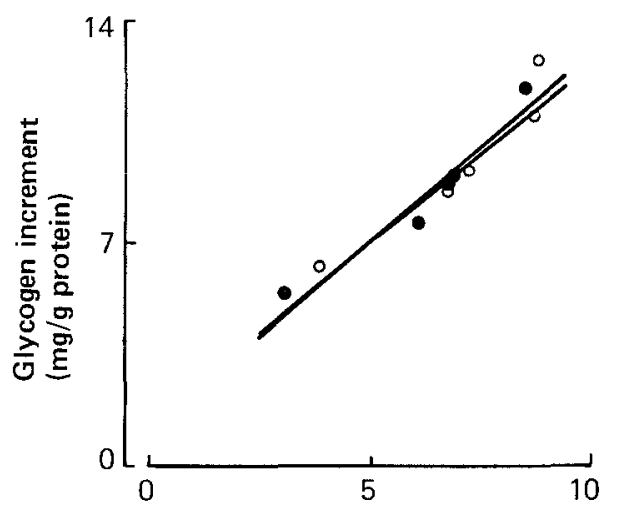

Glucose requirement $\left(\mathrm{mg} \cdot \mathrm{kg}^{-1} \cdot \mathrm{min}^{-1}\right)$
Fig. 2. The relationships between glucose requirement to maintain a glucose clamp and the increment in glycogen content of skeletal muscle during the clamp (right-hand panel), and between glucose requirement and glycogen synthase activity (lefthand panel) in patients with Type 1 diabetes. Patients are identified by solid circles when on injection therapy and open circles after a period of CSII. Calculated correlation coefficients were: glycogen synthase versus glucose requirement on injection therapy, $r=0.93, p<0.05$; on CSII, $r=0.89, p<0.05$; glycogen increment versus glucose requirement on injection therapy, $r=0.96, p<0.01$; on CSII, $r=0.95, p<0.02$
Table 3. Skeletal muscle glycogen content, glycogen synthase activity and pyruvate dehydrogenase activity in 6 control subjects and 5 Type 1 diabetic patients before and after a period of treatment by CSII

\begin{tabular}{lrl}
\hline & Fasting & End of clamp \\
\hline Glycogen content $(\mathrm{mg} / \mathrm{g}$ protein) & & \\
Injection therapy & $59.0 \pm 3.0$ & $67.0 \pm 3.0$ \\
CSII & $59.0 \pm 4.0$ & $69.0 \pm 3.0$ \\
Control subjects & $60.0 \pm 1.0$ & $77.0 \pm 1.0^{\mathrm{b}}$ \\
Glycogen synthase & & \\
Total (U/g wet wt.) & & \\
Injection therapy & $2.16 \pm 0.13$ & $2.18 \pm 0.10$ \\
CSII & $2.09 \pm 0.14$ & $2.10 \pm 0.13$ \\
Control subjects & $2.21 \pm 0.15$ & $2.33 \pm 0.10$ \\
Percent active (\%) & & \\
Injection therapy & $15.8 \pm 1.1$ & $25.5 \pm 3.0$ \\
CSII & $13.6 \pm 1.8$ & $28.1 \pm 3.4$ \\
Control subjects & $16.2 \pm 1.3$ & $37.2 \pm 2.1^{\mathrm{b}}$ \\
Pyruvate dehydrogenase & & \\
Total (U/g wet wt.) & & \\
Injection therapy & & \\
CSII & $0.77 \pm 0.07$ & $0.81 \pm 0.07$ \\
Control subjects & $0.82 \pm 0.09$ & $0.82 \pm 0.09$ \\
Percent active (\%) & $0.82 \pm 0.10$ & $0.85 \pm 0.09$ \\
Injection therapy & & \\
CSII & $9.9 \pm 0.6$ & $16.8 \pm 2.3$ \\
Control subjects & $14.1 \pm 2.7$ & $16.0 \pm 2.7$ \\
\hline
\end{tabular}

Mean \pm SEM.

a By analysis of variance the increase from "fasting" to "clamp" was significant for glycogen content $(p<0.001)$, percent active glycogen synthase $(p<0.001)$ and percent active pyruvate dehydrogenase $(p<$ 0.005 ), in the diabetic patients

${ }^{\mathrm{b}} p<0.05$ compared to diabetic patients

$(\mathrm{F}=24.4, p<0.001)$ was significantly higher on CSII $(9.5 \pm 2.5 \mathrm{mg} / \mathrm{g})$ than injection therapy $(8.5 \pm 2.4 \mathrm{mg} / \mathrm{g}$, $p<0.05$ ), but still below that of the control subjects $(17.9 \pm 2.1 \mathrm{mg} / \mathrm{g}, p<0.05)$. Analysis of variance confirmed a significant difference in glycogen increment between patients $(\mathrm{F}=31.5, p<0.01)$. This was highly correlated with clamp glucose requirement, $r=0.96$ on injections, and $r=0.95$ on CSII $(p<0.01$ and 0.02$)$
(Fig. 2). There was a similar correlation within the control subjects $(r=0.84, p<0.05)$.

Glucose-6-phosphate-stimulated (total) glycogen synthase activity did not change during either clamp study, and was not different between the two study days (Table 3). It was not different between patients and control subjects (Table 3). Although there were significant differences between subjects $(\mathrm{F}=20.3, p<0.001)$, this was not related to glucose requirement or muscle glycogen concentrations.

The expressed activity of skeletal muscle glycogen snythase in the basal state did not differ between the two study days, or between the patients and control subjects (Table 3 ). It was not related to total glycogen synthase activity. At the end of the clamp, expressed activity was significantly increased compared to the basal state (Table $3, \mathrm{~F}=46.8, p<0.001$ ), but was not significantly different between the two treatment regimens in this small group of patients $(0.05<p<0.1$, Table 3$)$. Activity in the patients was then lower than in the control subjects (Table $3, p<0.05$ ) on both study days.

Activity in individuals at the end of the clamps was, however, strongly correlated between the two treatment regimens ( $r=0.94, p<0.02)$. There were also significant differences in expressed glycogen synthase activity between patients $(\mathrm{F}=29.9, p<0.01)$. On injection therapy and CSII there were strong and significant correlations between expressed enzyme activity and muscle glycogen increment $(r=0.94, r=0.97 ; p<0.02$ and 0.01$)$, and between activity and glucose requirement $(r=0.93$ and $0.89, p<0.05$ ) (Fig. 2). Correlation was also found between enzyme activity in the control subjects and glucose requirement $(r=0.84, p<0.05)$, and possibly between activity and glycogen increment $(r=0.78$, $p<0.1$.

\section{Skeletal muscle pyruvate dehydrogenase}

Pyruvate dehydrogenase-phosphatase-stimulated (total) pyruvate dehydrogenase activity did not change 

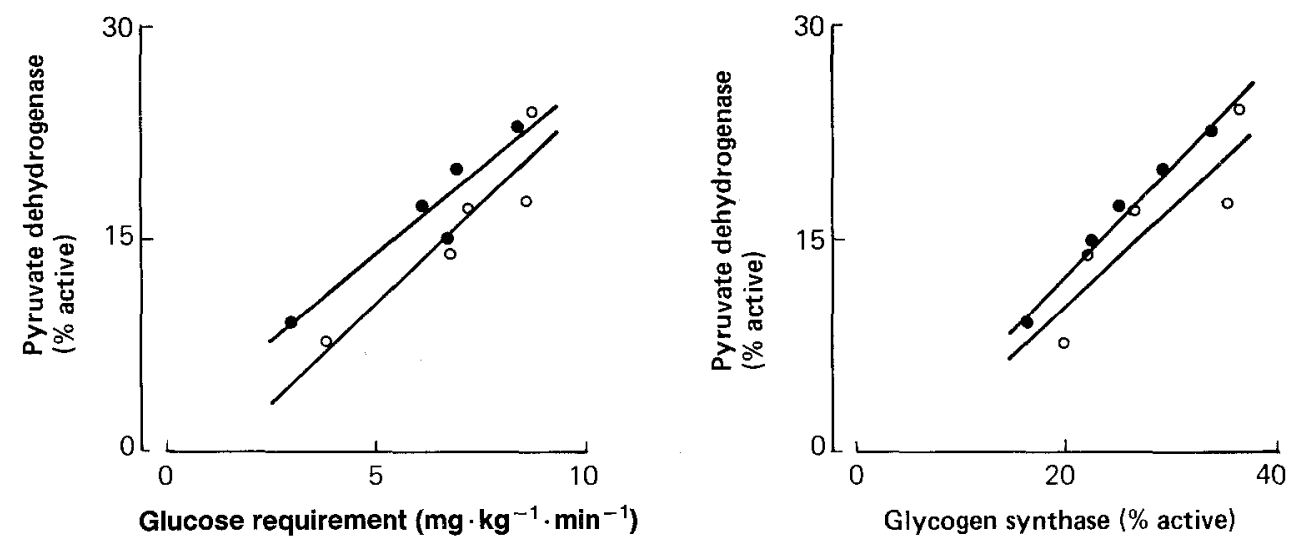

Fig. 3. The relationships between skeletal muscle pyruvate dehydrogenase activity and the glucose requirement to maintain a glucose clamp (lefthand panel), and between pyruvate dehydrogenase activity and glycogen synthase activity (right-hand panel) in patients with Type 1 diabetes. Patients are identified by closed circles when on injection therapy and open circles after a period on CSII. Calculated correlation coefficients were: pyruvate dehydrogenase ( $\%$ active) versus glucose requirement on injection therapy, $r=0.94, p<0.02$; on CSII, $r=0.94, p<0.02 ;$ pyruvate dehydrogenase ( $\%$ active) versus glycogen synthase (\% active) on injection therapy, $r=0.99, p<0.01$; on CSII, $r=0.88, p<0.05$

during either clamp study, and was not different between the two study days (Table 3 ). Though there were significant differences between patients $(\mathrm{F}=54.8, p<$ 0.001 ), this was not related to glucose requirement or total muscle glycogen synthase activity. Nor was total pyruvate dehydrogenase activity different from the control subjects (Table 3 ).

The expressed activity of skeletal muscle pyruvate dehydrogenase in the basal state did not differ between the two study days (Table 3), and was not related to total pyruvate dehydrogenase activity. At the end of the clamp, expressed activity was significantly increased compared to the basal state (Table $3, \mathrm{~F}=14.7, p<$ 0.005 ), but was not different between the two treatment regimens (Table 3). Activity was not significantly different from control subjects in either basal or clamp states (Table 3).

Activity in individuals was strongly correlated between the two treatments during the clamps ( $r=0.98$, $p<0.01$ ). There were significant differences in expressed pyruvate dehydrogenase activity between patients $(\mathrm{F}=222.4, p<0.001)$. On injection therapy and CSII there were strong and significant correlations between expressed enzyme activity and muscle glycogen synthase activity $(r=0.99, r=0.88 ; p<0.01$ and 0.05$)$, and activity and glucose requirement (both $r=0.94$, $p<0.02$ ) (Fig. 3).

\section{Discussion}

The hyperinsulinaemic euglycaemic clamp technique was introduced as a means of quantifying whole body insulin sensitivity in man without disturbing the confounding variables of insulin delivery or counter-regulatory hormones [6]. As in the present study insulin infusion rates giving concentrations somewhat above peak physiological post-prandial concentrations are used, in order to ensure suppression of hepatic glucose output (HGO). In severely resistant Type 2 (non-insulin-dependent) diabetic patients quantitation of $\mathrm{HGO}$ by isotopic methods may nevertheless be necessary, but this is not the case with Type 1 diabetic patients [1]. Though earlier studies using different methodology had suggested that insulin-treated diabetic patients might be insulin insensitive $[14,15]$, it has only become possible to demonstrate convincingly that this is the case with the glucose clamp technique [1]. Nevertheless, methodological problems remain in performing this type of study, and most reports to date have failed to consider whether the reported abnormalities are a consequence of Type 1 diabetes (or its treatment), or are secondary to the withdrawal of subcutaneous insulin overnight, as is necessary to perform a valid glucose clamp.

Unlike other studies comparing a group of patients on conventional therapy and CSII [2,3], we find very little change in sensitivity with improved outpatient control, glucose infusion rate on injection therapy already being $60 \%$ of the control group. This is possibly because we maintained blood glucose at normoglycaemic levels overnight before the clamps. The data of Del Prato et al. [16] suggests that overnight normoglycaemia prior to a glucose clamp improves glucose metabolic clearance rate, but this is complicated by the different glucose concentrations used for the clamps. Our clamps were also longer than is usual, in order to ensure steady state, provide an adequately measureable increment in muscle glycogen, and provide a reasonable time interval from any metabolic effects following the first muscle biopsy. It is possible that assessment of glucose disposal at lower insulin concentrations for a shorter time may have revealed greater differences between patients, as is suggested by the study of Pernet et al. [17].

Assessment of whole body insulin sensitivity begs the question as to which tissue(s), and more particularly which enzymatic site(s), are responsible for abnormal 
insulin mediated glucose metabolism. It is now well recognised, contrary to earlier studies [18], that hepatic glucose uptake is the smaller part of oral as well as clamp glucose disposal $[4,5]$. We chose to investigate skeletal muscle, as this forms the bulk of insulin-sensitive tissue in the body. Muscle mass is known to correlate with insulin sensitivity in normal subjects [19], and femoral vein catheter studies have suggested that most glucose entering the systemic circulation after a glucose load is taken up by muscle $[4,5]$.

Despite the small change in insulin sensitivity between insulin treatment regimens in the present study, it is noteworthy that this was reflected in greater clamp skeletal muscle glycogen deposition after CSII. Nevertheless, this was still lower (53\%) than in normal subjects. As there was a considerable and even spread in clamp glucose requirement in the subjects studied (Fig. 2), it has been possible to demonstrate that sensitivity to insulin, as measured by this method, correlates highly with glycogen deposition in skeletal muscle (Fig. 2). As body muscle represents around $40 \%$ of body mass [19], it may be calculated that around $60-70 \%$ of the glucose infused during the clamp appears as muscle glycogen, a figure which takes on a greater significance if allowance is made for non-insulin-dependent glucose metabolism by other tissues (around $20-30 \%$ of glucose infused). This suggests that peripheral insulin sensitivity in Type 1 diabetes is determined overwhelmingly by the metabolic pathway between plasma glucose and skeletal muscle glycogen.

A major regulatory enzyme on that pathway is glycogen synthase. This is known to be responsive to insulin in vivo at physiological insulin concentrations [20]. In the present study we failed to show any change in insulin-stimulated synthase activity between periods of conventional and intensive therapy, but it would be unsafe to conclude that there was no such change given the small number of subjects studied and the small change in insulin sensitivity. Certainly activity was lower than in control subjects. The large differences between patients allows the demonstration of a strong relationship of expressed glycogen synthase activity to both glycogen deposition during the clamp, and to clamp glucose requirement (Fig. 2).

These results are consistent with observations that insulin-mediated glucose uptake into muscle is mainly into non-oxidative pathways, and thus into glycogen [21]. In a mixed group of normal and glucose intolerant American Indians, Bogardus et al. [22] were able to correlate muscle glycogen synthase activity to glucose storage and insulin-mediated (clamp) glucose disposal, but failed to obtain correlations with glycogen deposition. This failure they attribute to the small and often unmeasurable change in glycogen concentration in muscle during their clamps. Our data show that these relationships hold in Type 1 diabetic patients and control subjects, and that glycogen deposition is indeed related to glucose requirement.
It would be easy to conclude that glycogen synthase was thus a strong candidate for the site of insulin resistance in Type 1 diabetes. However, pyruvate dehydrogenase showed the same relationship as glycogen synthase to clamp glucose requirement in the diabetic patients, though we could not find any differences from the normal subjects. It remains possible, however, that the changes in activity of either enzyme are secondary to alterations in the concentrations of metabolic intermediates. Such an activation defect could also affect other insulin regulated sites, and in particular the process of glucose transport into muscle and its phosphorylation.

Despite the differences in sensitivity between subjects, no evidence was found of any relationship between insulin clearance and insulin insensitivity. This data, obtained with immediate extraction of insulin antibodies [8], is consistent with previous results using the less accurate technique of antibody extraction on the day of assay [2,3]. As insulin is believed to be cleared largely through its receptor, and as binding abnormalities are not marked in Type 1 diabetes [23, 24], it would appear that the abnormality responsible for insulin insensitivity lies in the biochemical pathway by which the activated insulin receptor mediates the action of the hormone.

Total assayable activities of both glycogen synthase and pyruvate dehydrogenase proved to be unrelated to insulin sensitivity, preceding metabolic control, insulin dosage, and each other. Though the numbers of patients studied were small, the assay was sensitive enough to detect clear intra-patient differences. It may tentatively be concluded that synthesis of these enzymes is not disturbed in the treated Type 1 diabetic patient.

We therefore conclude that: (1) the euglycaemic glucose clamp is an excellent predictor of biochemical changes in skeletal muscle in Type 1 diabetes; (2) preceding metabolic control has a relatively small effect on insulin sensitivity in these patients, provided overnight control is maintained prior to the clamp; (3) the defect in glucose disposal lies in the pathway of formation of glycogen in skeletal muscle; (4) the primary biochemical abnormality may nevertheless lie in the pathway by which insulin, once bound to the receptor, alters the activity of sensitive enzymes.

Acknowledgements. We thank the staff of Ward 15, Freeman Hospital, for assistance in patient care. The study was supported by the Newcastle Health Authority, the Wellcome Trust, the Medical Research Council and the British Diabetic Association. Dr. S. Yeaman kindly provided pyruvate dehydrogenase phosphatase and Dr. R. Denton the coupling agent.

\section{References}

1. DeFronzo RA, Hendler R, Simonson D (1982) Insulin resistance is a prominent feature of insulin dependent diabetes. Diabetes 31: 795-801

2. Yki-Jarvinen $H$, Koivisto $V(1984)$ Continuous subcutaneous insulin infusion therapy decreases insulin resistance in type 1 diabetes. J Clin Endocrinol Metab 58: 659-666 
3. Lager I, Lonroth P, Von-Schenk H, Smith U (1983) Reversal of insulin resistance in Type 1 diabetes after treatment with continuous subcutaneous insulin infusion. Br Med J 287: 1661-1664

4. Katz LD, Glickman MG, Rapopart S, Ferrannini E, DeFronzo RA (1983) Splanchnic and peripheral disposal of oral glucose in man. Diabetes 32: 675-679

5. DeFronzo RA, Ferrannini E, Hendler R, Felig P, Wahren J (1983) Regulation of splanchnic and peripheral glucose uptake by insulin and hyperglycaemia in man. Diabetes $32: 35-45$

6. Edwards RHT, Round JM, Jones DA (1983) Needle biopsy of skeletal muscle: a review of 10 years experience. Muscle Nerve 6: 676-683

7. DeFronzo RA, Tobin JD, Andres R (1979) Glucose clamp technique: a method for quantifying insulin secretion and resistance. Am J Physiol 237: E214-E223

8. Hanning I, Home PD, Alberti KGMM (1985) Measurement of free insulin concentrations: the influence of the timing of extraction of insulin antibodies. Diabetologia 28: 831-836

9. Golden S, Wals PA, Katz J (1977) An improved procedure for the assay of glycogen synthase and phosphorylase in rat liver homogenates. Anal Biochem 77: 436-445

10. Coore HG, Denton RM, Martin BR, Randle PJ (1971) Regulation of adipose tissue pyruvate dehydrogenase by insulin and other hormones. Biochem J 125: 115-127

11. Tabor H, Mehler AH, Stadtman ER (1953) The enzymatic acetylation of amines. J Biol Chem 204: 127-138

12. Keppler D, Decker K (1974) Glycogen determination with amyloglucosidase. In: Bergmeyer HU (ed) Methods of enzymatic analysis. Academic, New York, p 1127-1131

13. Lowry OH, Roseborough NJ, Farr, Randall RJ (1951) Protein measurement with the Folin phenol reagent. J Biol Chem 193: 256-275

14. Ginsberg HN (1977) Investigation of insulin sensitivity in ketosis prone diabetes mellitus. Diabetes 26: 278-283

15. Harano Y, Ohgaku S, Kosugi K, Yasuda H, Nakano T, Kobayashi M, Hidaka H, Izumi K, Kashiwagi A, Shigeta Y (1980) Clinical significance of altered insulin sensitivity in diabetes mellitus assessed by glucose, insulin, and somatostatin infusion. J Clin Endocrinol Metab 52:982-987
16. Del Prato S, Nosadini R, Tiengo A, Tessari P, Avogaro A, Trevisan R, Valerio A, Muggeo M, Cobelli C, Toffolo G (1983) Insulin-mediated glucose disposal in type 1 diabetes: evidence for insulin resistance. J Clin Endocrinol Metab 57: 904-910

17. Pernet A, Trimble ER, Kuntschen F, Damoiseaux P, Assal J-Ph, Hahn C, Renold AE (1984) Insulin resistance in type 1 (insulindependent) diabetes: dependance on plasma insulin concentration. Diabetologia 26: $255-260$

18. Felig P, Wahren J, Hendler R (1975) Influence of oral glucose ingestion on splanchnic glucose and gluconeogenic substrates metabolism in man. Diabetes 24: 468-475

19. Yki-Jarvinen H, Koivisto VA (1983) Effects of body composition on insulin sensitivity. Diabetes 32:965-969

20. Kruszynska YT, Home PD, Alberti KGMM (1986) The in vivo regulation of liver and muscle glycogen synthase activity by glucose and insulin. Diabetes 35: 662-667

21. DeFronzo RA, Jacot E, Jequier E, Maeder E, Felber JP (1981) The effect of insulin on the disposal of intravenous glucose: results from indirect calorimetry and hepatic and femoral venous catheterisation. Diabetes 30: 1000-1007

22. Bogardus C, Lillioja S, Stone K, Mott D (1984) Correlation between muscle glycogen synthase activity and in vivo insulin action in man. J Clin Invest 73: 1185-1190

23. Pedersen O, Beck-Nielsen H, Heding L (1978) Insulin receptors on monocytes from patients with ketosis-prone diabetes mellitus. Diabetes 27: 1098-1104

24. Pedersen $\mathrm{O}, \mathrm{Hjollund} \mathrm{E}$ (1982) Insulin receptor binding to fat and blood cells and insulin action in fat cells from insulin-dependent diabetics. Diabetes 31: 706 -715

Received: 14 April 1986

and in revised form: 26 August 1986

\author{
Dr. Y.T. Kruszynska \\ Department of Medicine \\ Medical School \\ Framlington Place \\ Newcastle upon Tyne NE2 4HH \\ UK
}

